\title{
PELABELAN SELIMUT TOTAL SUPER (a,d)-H ANTIMAGIC PADA GRAPH LOBSTER BERATURAN $L_{n}(q, r)$
}

\author{
Tira Catur Rosalia ${ }^{1 \S}$, Luh Putu Ida Harini ${ }^{2}$, Kartika Sari $^{3}$ \\ ${ }^{1}$ Jurusan Matematika, Fakultas MIPA - Universitas Udayana [Email: mathematira@gmail.com] \\ ${ }^{2}$ Jurusan Matematika, Fakultas MIPA - Universitas Udayana [Email: ballidah@unud.ac.id] \\ ${ }^{3}$ Jurusan Matematika, Fakultas MIPA - Universitas Udayana [Email: sarikaartika@ unud.ac.id] \\ ${ }^{\S}$ Corresponding Author
}

\begin{abstract}
Graph labelling is a function that maps graph elements to positive integers. A covering of graph $G$ is $H_{i}$ family subgraph from $G$, for $1 \leq i \leq k$ with integer $k$. Graph $G$ admits $H$ covering if for every subgraph $H_{i}$ is isomorphic to a graph $H$. A connected graph $G(V, E)$ is an $(a, d)$-antimagic if there are positive integers $a, d$ and bijective function $f: E(G) \rightarrow\{1,2,3, \ldots,|E(G)|\}$ such that there are injective function $g_{f}: V \rightarrow N$, defined by $g_{f}(v)=\sum\{f(u v) \mid u v \in E(G)\}$ with $g_{f}(V)=\{a, a+$ $d, \ldots,(|V|-1) d\}$. The purpose of this research is to determine a total super $(a, d)-H$ antimagic covering on lobster graph $L_{n}(q, r)$. The method of this research is literature study method. It is obtained that there are a total super $\left(2 n q^{2} r^{2}+3 n q^{2}+4 n q r^{2}+7 n q r-12 n q+6 n r q^{2}-16 n r-\right.$ $22 n+d+1, d)-L_{2}(q, r)$ antimagic covering for $d \in\{1,3\}$ on lobster graph $L_{n}(q, r)$ with integer $n \geq 3, r \geq 1$, and even number $q \geq 2$.
\end{abstract}

Keywords: total super $(a, d)-H$ antimagic covering, lobster graph, bat graph.

\section{PENDAHULUAN}

Teori graph merupakan salah satu cabang ilmu matematika yang dapat diaplikasikan ke dalam berbagai bidang ilmu, di antaranya pada bidang teknologi informasi dan komunikasi, kimia, dan biologi. Salah satu materi dalam teori graph yang sering dibahas adalah pelabelan graph. Pelabelan graph diterapkan antara lain pada Mobile Adhoc Networks (MANETS), pengamanan dan routing otomatis pada jaringan, X-Ray Crystallographic analysis, Design Communication Network addressing Systems, menentukan Optimal Circuit Layouts dan RadioAstronomy (Prasanna, 2014), coding theory, radar (Hegde, 2012), penyusunan chipertext (kode) dalam kriptografi (Azizah dan Dafik, 2015), serta beberapa bidang lainnya.

Pelabelan graph merupakan suatu pemetaan dari elemen graph ke bilangan bulat positif. Pada umumnya domain (daerah asal) dari pelabelan adalah himpunan sisi dan titik (disebut pelabelan total), himpunan titik saja (pelabelan titik), atau himpunan sisi (pelabelan sisi) (Wailis, 2001). Terdapat dua jenis pelabelan graph, yaitu pelabelan magic dan antimagic.
Sebuah graph dengan $q$ sisi disebut graph antimagic apabila semua sisi dilabeli dengan bilangan positif $1,2, \ldots, q$ tanpa pengulangan, sedemikian sehingga bobot setiap titiknya berbeda (Hartsfield dan Ringel, 1990). Salah satu jenis pelabelan graph yang banyak diteliti adalah pelabelan selimut.

Pelabelan selimut pertama kali diperkenalkan oleh Gutiérrez dan Lladó (2005). Diberikan graph sederhana $H$, graph $G(V, E)$ dikatakan mengandung $H$-covering apabila setiap sisi pada $E(G)$ yang merupakan subgraph dari $G$, isomorfik terhadap $H$. Selain itu, dalam bukunya Gallian (2015) telah menuliskan definisi pelabelan $(a, d)$ - antimagic. Graph terhubung $G:(V: E)$ dikatakan graph $(a, d)$ antimagic apabila terdapat bilangan bulat positif $a, d \quad$ dan fungsi bijektif $f: E(G) \rightarrow\{1,2,3, \ldots,|E(G)|\} \quad$ sedemikian sehingga terdapat pemetaan injektif $g_{f}: V \rightarrow N$ yang didefinisikan sebagai $g_{f}(v)=$ $\sum\{f(u v) \mid u v \in E(G)\}$ dengan $\quad g_{f}(V)=$ $\{a, a+d, \ldots,(|V|-1) d\}$ (Gutiérrez dan Lladó, 
2005).

Inayah et al (2009) mendefinisikan pelabelan selimut total $(a, d)-H$ antimagic dari graph $\mathrm{G}$ merupakan fungsi bijektif $\xi$ dari $V \cup E \quad$ ke $\quad\{1,2, \ldots,|V|+|E|\}$ untuk semua subgraph $H^{\prime}$ yang isomorfik terhadap $H$, dengan bobot- $H$ yang dirumuskan sebagai

$$
w\left(H^{\prime}\right)=\sum_{v \in V\left(H^{\prime}\right)} \xi(v)+\sum_{e \in V\left(H^{\prime}\right)} \xi(e)
$$

Pelabelan ini membentuk barisan aritmetika $a, a+d, a+2 d, \ldots, a+(t-1) d$ dengan $a$ dan $d$ merupakan bilangan bulat positif dan $t$ adalah banyak subgraph $G$ yang isomorfik dengan $H$. Pelabelan $\xi$ disebut sebagai pelabelan total super $(a, d)-H \quad$ antimagic apabila $\xi(V)=\{1,2, \ldots,|V|\}$ (Gallian, 2015).

Penelitian mengenai pelabelan selimut total super $(a, d)-H$ antimagic telah cukup banyak dibahas dengan berbagai macam graph. Sari (2014) melakukan pelabelan pada graph pohon pisang, kembang api, dan buku. Pada tahun yang sama, Kathiresan et al (2015) juga melakukan pelabelan yang sama pada Star Related Graphs, dengan ini graph yang digunakan adalah graph Bintang $S_{n}$ dan graph Caterpillar.

Dari beberapa penelitian yang telah dilakukan mengenai pelabelan selimut total super $(a, d)-H$ antimagic, sejauh ini belum ditemukan penelitian yang membahas tentang graph lobster. Graph lobster merupakan salah satu jenis dari graph pohon yang memiliki pola simetris. Mengacu pada penelitian serupa dengan beberapa graph yang relevan serta untuk lebih mengembangkan penelitian mengenai pelabelan selimut total super $(a, d)-H$ antimagic, tujuan dari penelitian adalah menentukan pelabelan selimut total super $(a, d)-H$ antimagic pada graph lobster beraturan $L_{n}(q, r)$.

Guna membatasi masalah agar tidak terlalu luas, dalam penelitian ini penulis memberikan batasan masalah sebagai berikut :

1. Graph $L_{2}(q, r)$ digunakan sebagai selimut untuk pelabelan graph lobster beraturan $L_{n}(q, r)$.

2. Graph lobster $L_{n}(q, r)$ yang akan dilabeli memiliki jarak maksimum $t=2$.

\section{TINJAUAN PUSTAKA}

Selanjutnya, diberikan beberapa teori yang mendasari penelitian ini.

\subsection{Graph Lobster}

Graph lobster merupakan salah satu jenis dari graph pohon (tree). Berikut diberikan definisi graph lobster.

Definisi 2.1 (Khan, Pal, dan Pal, 2009) Graph lobster adalah suatu graph pohon yang mengandung lintasan (dengan panjang maksimum) di mana setiap simpul lain dari graph tersebut memiliki jarak maksimum $t$ terhadap lintasan, dengan $t$ adalah bilangan bulat.

Gambar 1 merupakan contoh graph lobster yang memiliki jarak maksimum $t=3$.

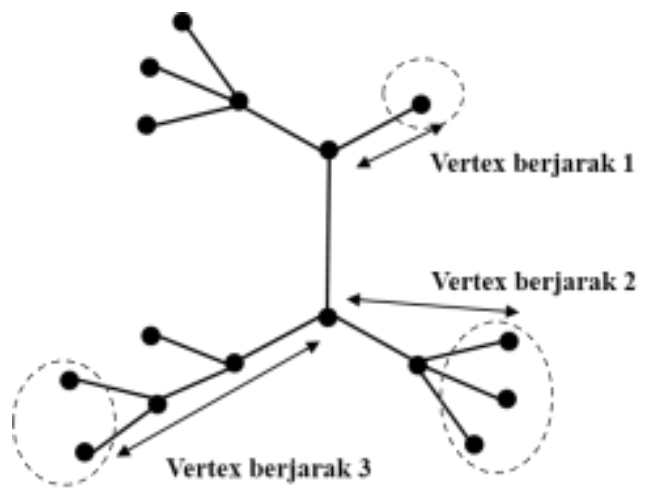

Gambar 1. Graph lobster dengan jarak maksimum

$$
\boldsymbol{t}=\mathbf{3}
$$

Graph lobster $L_{n}(q, r)$ merupakan graph lobster teratur yang memiliki $n$ vertex backbone sebagai lintasan utama, setiap vertex backbone berhubungan dengan $q$ vertex hand dan setiap vertex hand berhubungan dengan $r$ vertex finger, ( $n, r \in N, n \geq 2$, dan $q$ genap) (Gumilar et al, 2013).

\subsection{Multi himpunan $k$-seimbang}

Didefinisikan bahwa multi himpunan adalah himpunan yang memperbolehkan adanya elemen-elemen yang sama dalam satu himpunan. Pada penelitian ini, notasi $[a, b]=$ $\{x \in N \mid a \leq x \leq b\}$. Selain itu. didefinisikan pula gabungan dari multihimpunan, yang disimbolkan dengan $\biguplus$, yaitu $\{a\} \biguplus\{a, b\}=$ $\{a, a, b\}$. Berikut diberikan definisi dan lemma terkait dengan multihimpunan $k$-seimbang. 
Definisi 2.2 (Roswitha et al, 2013) Diberikan $k \in N$ dan $X$ adalah multi himpunan yang berisi bilangan bulat positif. Multi himpunan $X$ dinamakan $k$-seimbang apabila terdapat $k$ himpunan bagian dari $X$ dinamakan $X_{1}, X_{2}, X_{3}, \ldots, X_{k}$, sedemikian sehingga setiap $i \in[1, k], \quad$ berlaku $\left|X_{i}\right|=\frac{|X|}{k}, \sum X_{i}=\frac{\sum X}{k} \in N$, $\biguplus_{i=1}^{k} X_{i}=X$. Untuk setiap $i \in[1, k], X_{i}$ disebut himpunan bagian seimbang dari $X$.

\section{METODE PENELITIAN}

Metode penelitian yang digunakan dalam penelitian ini adalah kajian pustaka yaitu dengan mengumpulkan dan mengkaji referensi berupa buku, skripsi, jurnal maupun tulisan dari perpustakan dan situs web.

Langkah-langkah yang dilakukan dalam penelitian ini diuraikan sebagai berikut:

1. Mempelajari penelitian sebelumnya mengenai pelabelan selimut total super $(a, d)-H$ antimagic. Pada tahap ini akan diulas kembali tentang definisi dasar, contoh-contoh dan beberapa sifat yang menjadi landasan penelitian selanjutnya.

2. Mengkonstruksikan graph yang dilabelkan, yaitu graph lobster beraturan $L_{n}(q, r)$.

3. Menentukan bobot selimut $H$-terbesar dan bobot selimut $H$-terkecil.

4. Menentukan batas atas $d$ untuk tiap kelas graph yang akan dicari pelabelannya.

5. Membuat lemma-lemma yang diperoleh dari penurunan lemma teknik multihimpunan $k$ seimbang.

6. Menentukan pelabelan sisi dan pelabelan titik. yang dipartisi dengan menggunakan teknik multihimpunan $k$-seimbang. Penggunaan teknik ini dapat menghasilkan bobot $H_{i}$ dengan $1 \leq i \leq n$ yang membentuk suatu barisan aritmatika.

7. Menentukan bentuk pola umum pelabelan selimut total super $(a, d)-H$ antimagic pada graph lobster beraturan $L_{n}(q, r)$.

8. Menentukan bobot selimut serta nilai $a$ dan $d$ pada pola pelabelan selimut total super $(a, d)-H$ antimagic yang diperoleh.
9. Membangun beberapa teorema untuk membuktikan kebenaran dari pola umum pelabelan.

\section{HASIL DAN PEMBAHASAN}

Sebelum melakukan pelabelan selimut total super $(a, d)-L_{2}(q, r)$ antimagic pada graph lobster $L_{n}(q, r)$, diberikan lemma multi himpunan $k$-seimbang yang digunakan dalam mendukung pola pelabelan,

\subsection{Multi himpunan $k$-seimbang}

Definisi dari multi himpunan $k$-seimbang telah disajikan pada Definisi 2.2. Selanjutnya, definisi tersebut digunakan sebagai dasar untuk mendapatkan Lemma 4.1.

Lemma 4.1 Jika $k, x, y \geq 2$ bilangan bulat non negatif maka multi himpunan $X=[x, x+$ $2 k y-1]$ merupakan multi himpunan $k$ seimbang.

Bukti. Ambil sebarang $k, x, y \geq 2$ bilangan bulat positif. Dibentuk subhimpunan $X_{i}=$ $\left\{a_{i j}, b_{i j}, 0 \leq j \leq y-1\right\} \quad$ untuk $\quad i \in[1, k]$, dengan

$$
\begin{aligned}
& \quad a_{i j}=x+y(i-1)+j ; \\
& \quad b_{i j}=x+2 k y-y(i-1)-j-1 ; \\
& \text { untuk } 0 \leq j \leq y-1
\end{aligned}
$$

Selanjutnya dibentuk dua multi himpunan $A$ dan $B$ untuk $i \in[1, k]$ yaitu

$$
\begin{aligned}
A= & \left\{a_{i j} \mid a_{i j}=x+y(i-1)+j, 0 \leq j \leq y-1\right\} \\
= & {[x, x+y k-1] ; } \\
B= & \left\{b_{i j} \mid \begin{array}{c}
b_{i j}=x+2 k y-y(i-1)-j-1, \\
0 \leq j \leq y-1
\end{array}\right\} \\
= & {[x+k y, x+2 k y-1] . } \\
& \text { Dengan memperhatikan multi himpunan } X
\end{aligned}
$$
dan $X_{i}$, diperoleh bahwa untuk setiap $i \in[1, k],|X|=2 k y$ dan $\left|X_{i}\right|=2 y$ sehingga dapat dituliskan sebagai persamaan $\left|X_{i}\right|=\frac{|X|}{k}$. Diperhatikan bahwa jumlah elemen pada $X_{i}$ adalah sebagai berikut

$$
\begin{aligned}
\sum X_{i} & =\sum_{j=0}^{y-1} a_{i j}+\sum_{j=0}^{y-1} b_{i j} \\
& =2 x y+2 k y^{2}-y .
\end{aligned}
$$

Selain itu, jumlah setiap elemen pada $X_{i+1}$ adalah sebagai berikut. 


$$
\begin{aligned}
\sum X_{i+1} & =\sum_{j=1}^{y-1} a_{j}^{i+1}+\sum_{j=1}^{y-1} b_{j}^{i+1} \\
& =2 x y+2 k y^{2}-y .
\end{aligned}
$$

Dengan memperhatikan persamaan (1) dan (2), diperoleh $\sum X_{i+1}=\sum X_{i}$. Diperhatikan pula bahwa jumlah elemen pada himpunan $X$ adalah

$$
\begin{aligned}
\sum X & =\sum_{n=x}^{x+2 k y-1} n \\
& =2 k x y+2 k^{2} y^{2}-k y
\end{aligned}
$$

Hal ini berarti untuk setiap $i \in[1, k]$, $\sum X_{i}=\frac{\sum X}{k}$. Selain itu, dapat dilihat bahwa $A \biguplus B=X$ dan dengan memperhatikan elemenelemen dari $X_{i}$ dan $X$ diperoleh $\biguplus_{i=1}^{3} X_{i}=X$. Berdasarkan definisi multi himpunan $k$-seimbang, dapat disimpulkan bahwa multi himpunan $X=[x, x+2 k y-1]$ merupakan multi himpunan $k$-seimbang.

Sebagai ilustrasi penggunaan Lemma 4.1 berikut diberikan Contoh 4.2.

Contoh 4.2 Diberikan $X=[10,33]$ dan diambil bilangan bulat positif $k, x, y \geq 2$. Untuk $x=10$, diperoleh $k y=24$. Nilai $k$ yang mungkin adalah $2,3,4,6,12$, sehingga $X=[10,33]$ dapat dibentuk menjadi multi himpunan $k$-seimbang dengan $k=2,3,4,6,12$.

\subsection{Pelabelan Selimut Total Super $(a, d)-$ $L_{2}(q, r)$ antimagic pada Graph Lobster $L_{n}(q, r)$}

Sebelum membahas pola pelabelan, akan dicari banyak subgraph $L_{n}(q, r)$ yang isomorfik terhadap selimut $L_{2}(q, r)$ yang disimbolkan dengan $s$. Diperhatikan bahwa pada graf $L_{3}(q, r)$, memiliki dua subgraph yang isomorfik terhadap selimut $L_{2}(q, r)$ yang disajikan pada Gambar 2. Bagian yang diberi warna coklat merupakan subgraph dari $L_{3}(q, r)$ yang isomorfik terhadap $L_{2}(q, r)$.

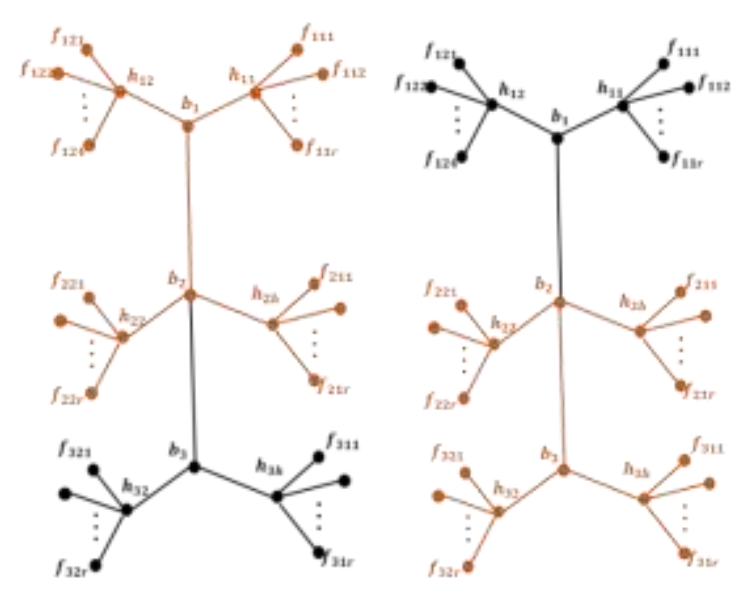

Gambar 2. Graf lobster $\boldsymbol{L}_{\mathbf{3}}(\boldsymbol{q}, \boldsymbol{r})$, dengan dua subgraph yang isomorfik terhadap selimut $\boldsymbol{L}_{2}(\boldsymbol{q}, \boldsymbol{r})$

Dengan memperhatikan pola graf selanjutnya dengan $n$ yang lebih besar diperoleh bahwa banyak subgraph $L_{n}(q, r)$ yang isomorfik terhadap selimut $L_{2}(q, r)$ adalah $n-1$, dengan $n \geq 3$.

Pada pelabelan selimut total super $(a, d)-H$ antimagic, nilai $d$ merupakan selisih dari jumlah label selimut $H$. Diberikan batas maksimum nilai $d$ pada Lemma 4.3.

Lemma 4.3. Jika graph lobster $L_{n}(q, r)$ adalah $(a, d)-L_{2}(q, r)$ antimagic total super, maka untuk $n \geq 3$ diperoleh nilai

$$
\begin{aligned}
d \leq & \frac{4 n q^{2}+16 n q r+7 n q+16 n r^{2}+14 n r+3 n-8 q^{2}}{n-2} \\
& -\frac{32 q r+14 q+32 r^{2}+28 r+6}{n-2}
\end{aligned}
$$

Bukti. Diberikan $G$ adalah graph lobster $L_{n}(q, r)$ dan $H$ adalah graph lobster $L_{2}(q, r)$ dengan

$$
\begin{aligned}
& |V(G)|=v_{G}=n(1+q+q r) ; \\
& |E(G)|=e_{G}=n(1+q+q r)-1 ; \\
& |V(H)|=v_{H}=2(1+q+q r) ; \\
& |E(H)|=e_{H}=2 q+2 q r+1 .
\end{aligned}
$$

Misalkan $\xi$ adalah fungsi bijektif dari $E(G) \cup V(G)$ pada $\{1,2,3, \ldots,|V(G)|+|E(G)|\}$ dengan $\xi(V(G))=\{1,2,3, \ldots, V(G)\} \quad$ dan $\xi(E(G))=\{V(G)+1, V(G)+2, \ldots, V(G)+$ $E(G)\}$. Dimisalkan $\omega\left(H_{h}\right)$ adalah bobot selimut $H$ untuk $1 \leq h \leq s$. Diperoleh bobot selimut $H$ terbesar adalah

$\omega\left(H_{s}\right)=\sum_{v \in V\left(H_{s}\right)} \xi(v)+\sum_{e \in E\left(H_{s}\right)} \xi(e)$. 
Diperhatikan bahwa jumlah label vertex

$$
\sum_{v \in V\left(H_{S}\right)} \xi(v) \leq \sum_{i=0}^{v_{H}-1} v_{G}-i
$$

dan jumlah label edge

$$
\sum_{e \in E\left(H_{S}\right)} \xi(e) \leq \sum_{i=0}^{e_{H}-1}\left(v_{G}+e_{G}-i\right) .
$$

Selanjutnya, persamaan (3) dapat dituliskan sebagai suatu pertidaksamaan yaitu

$\omega\left(H_{S}\right) \leq \sum_{i=0}^{v_{H}-1} v_{G}-i+\sum_{i=0}^{e_{H}-1}\left(v_{G}+e_{G}-i\right)$

Karena graph $G$ adalah total super $(a, d)-$ $H$ antimagic maka bobot selimut $H$ terbesar adalah $a+(s-1) d$. Meninjau dari pertidaksamaan (3) diperoleh

$$
\begin{aligned}
a+(s-1) d \leq & \sum_{i=0}^{v_{H}-1} v_{G}-i \\
& +\sum_{i=0}^{e_{H}-1}\left(v_{G}+e_{G}-i\right) \\
= & 6 n q^{2} r^{2}+6 n q^{2}+10 n q r+10 n q \\
& +12 n r q^{2}+4 n-4 q^{2} r^{2}-4 q^{2} \\
& -6 q r-6 q-8 r q^{2}-2 .
\end{aligned}
$$

Selain itu, diperoleh bobot selimut $H$ terkecil adalah

$\omega\left(H_{1}\right)=\sum_{v \in V\left(H_{1}\right)} \xi(v)+\sum_{e \in E\left(H_{1}\right)} \xi(e)$.

Diperhatikan bahwa jumlah label vertex adalah

$$
\sum_{v \in V\left(H_{1}\right)} \xi(v) \geq \sum_{i=1}^{v_{H}} i
$$

dan jumlah label edge

$$
\sum_{e \in E\left(H_{1}\right)} \xi(e) \geq \sum_{i=1}^{e_{H}}\left(v_{G}+i\right) .
$$

Selanjutnya, persamaan (6) dapat dituliskan sebagai suatu pertidaksamaan yaitu

$$
\omega\left(H_{1}\right) \geq \sum_{i=1}^{v_{H}} i+\sum_{i=1}^{e_{H}}\left(v_{G}+i\right) .
$$

Karena graph $G$ adalah total super $(a, d)-$ $H$ antimagic maka bobot selimut $H$ terkecil adalah $a$. Meninjau dari pertidaksamaan (7) diperoleh

$a \geq \sum_{i=1}^{v_{H}} i+\sum_{i=1}^{e_{H}}\left(v_{G}+i\right)$

$$
\begin{aligned}
= & 2 n q^{2} r^{2}+2 n q^{2}+3 n q r+3 n q+4 n r q^{2} \\
& +n+4 q^{2} r^{2}+4 q^{2}+8 q r+8 q+8 r q^{2} \\
& +4 .
\end{aligned}
$$

Dengan mengurangkan pertidaksamaan (5) dan (8) diperoleh

$$
\begin{gathered}
(s-1) d \leq\left(6 n q^{2} r^{2}+6 n q^{2}+10 n q r+10 n q\right. \\
+12 n r q^{2}+4 n-4 q^{2} r^{2}-4 q^{2} \\
\left.-6 q r-6 q-8 r q^{2}-2\right) \\
-\left(2 n q^{2} r^{2}+2 n q^{2}+3 n q r+3 n q\right. \\
+4 n r q^{2}+n+4 q^{2} r^{2}+4 q^{2}+8 q r \\
\left.+8 q+8 r q^{2}+4\right) \\
\Leftrightarrow d \leq \frac{4 n q^{2}+16 n q r+7 n q+16 n r^{2}+14 n r+3 n-8 q^{2}}{n-2} \\
-\frac{32 q r+14 q+32 r^{2}+28 r+6}{n-2} .
\end{gathered}
$$

Pada graph lobster $L_{n}(q, r)$, diperoleh nilai maksimum

$$
d=\left\lfloor\begin{array}{c}
\frac{4 n q^{2}+16 n q r+7 n q+16 n r^{2}+14 n r+3 n-8 q^{2}}{n-2} \\
-\frac{32 q r+14 q+32 r^{2}+28 r+6}{n-2}
\end{array}\right\rfloor,
$$

dengan $n \geq 3$.

Sebagai contoh, dilakukan pelabelan total super $(a, d)-L_{2}(2,4)$ antimagic pada graph lobster $L_{3}(2,4)$ dengan $d=473$ yang diilustrasikan berikut.

Contoh 4.4 Dimisalkan himpunan label untuk graph lobster $L_{3}(2,4)$ adalah $X=[1,33]$ dan $Y=[34,65]$. Elemen $X$ digunakan untuk melabeli vertex-vertex pada graph lobster $L_{3}(2,4)$. Himpunan $X$ dipartisi menjadi tiga subhimpunan, dengan untuk setiap $i \in[1,3]$ diperoleh subhimpunan $X_{i}$ adalah

$$
X_{1}=[1,11] ; X_{2}=[12,22] ; \quad X_{3}=[23,33] \text {. }
$$

Elemen subhimpunan $X_{i}$ digunakan untuk melabeli vertex $b_{i}, h_{i j}$, dan $f_{i j k}$ untuk $1 \leq j \leq 2$ dan $1 \leq k \leq 8$. Jumlah elemen subhimpunan $X_{i}$ untuk setiap $i \in[1,3]$ adalah $\sum X_{i}=121 i-55$.

Elemen $Y$ digunakan untuk melabeli edgeedge pada graph lobster $L_{3}(2,4)$. Himpunan $Y$ dipartisi menjadi 2 himpunan, $B=\{44,55\}$ dan $F=[34.43] \biguplus[45,54] \biguplus[56,65]$. Himpunan $F$ dipartisi menjadi tiga subhimpunan, dengan untuk setiap $i \in[1,3]$ diperoleh subhimpunan $F_{i}$ adalah

$F_{1}=[34.43] ; F_{2}=[45,54] ; F_{3}=[56,65]$.

Elemen subhimpunan $F_{i}$ digunakan untuk melabeli edge yang menghubungkan vertex $b_{i}$ 
dengan $h_{i j}$, dan vertex $h_{i j}$ dengan $f_{i j k}$ untuk $1 \leq j \leq 2$ dan $1 \leq k \leq 8$. Elemen subhimpunan $B_{h}$ digunakan untuk melabeli edge yang menghubungkan vertex $b_{h}$ dengan $b_{h+1}$ untuk $1 \leq h \leq 2$. Jumlah elemen subhimpunan $F_{i}$ untuk setiap $i \in[1,3]$ adalah $\sum F_{i}=110 i+275$ , dan jumlah subhimpunan $B_{i}$ adalah $\quad B_{i}=$ $11 i+33$.

Pada graph lobster $L_{3}(2,4)$ terdapat 2 subgraph yang isomorfik dengan $L_{2}(2,4)$. Dimisalkan $\omega\left(H_{h}\right)$ untuk $1 \leq h \leq 2$ adalah bobot setiap subgraph lobster $L_{n}(q, r)$ yang isomorfik dengan $L_{2}(q, r)$. Kemudian untuk setiap $1 \leq h \leq 2$ diperoleh

$$
\begin{aligned}
\omega\left(H_{h}\right) & =\sum_{i=0}^{1} X_{i+h}+\sum_{i=0}^{1} F_{i+h}+B_{h} \\
& =473 h+704 .
\end{aligned}
$$

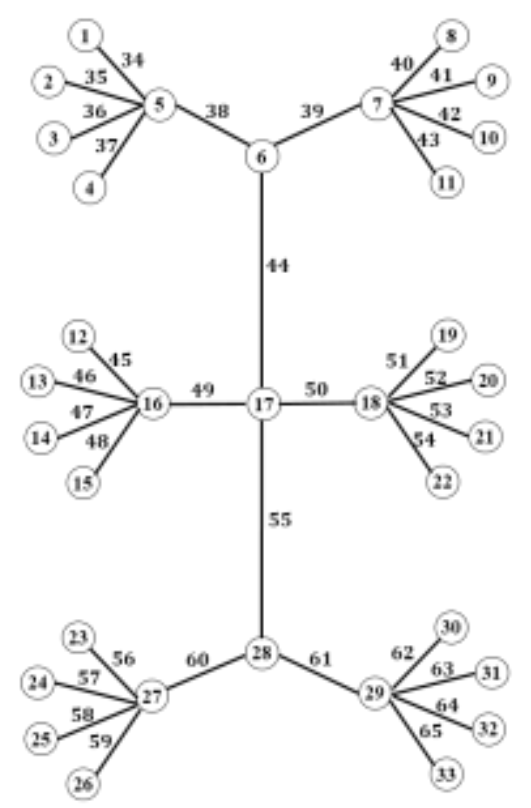

Gambar 3. Pelabelan selimut total super $(\mathbf{1 2 2 1}, \mathbf{4 7 3})-\boldsymbol{L}_{\mathbf{2}}(\mathbf{2}, \mathbf{4})$ antimagic pada graph lobster $\boldsymbol{L}_{\mathbf{3}}(\mathbf{2}, \mathbf{4})$

Sehingga diperoleh nilai $d=\omega\left(H_{h+1}\right)-\omega\left(H_{h}\right)=473$ dan $a=1221$. Hasil pelabelan selimut total super $(1221,473)-L_{2}(2,4)$ antimagic pada graph lobster $L_{3}(2,4)$ disajikan pada Gambar 3.3.

Pola pelabelan selimut total super $(a, 1)-$ $L_{2}(q, r)$ antimagic pada graph lobster $L_{n}(q, r)$ disajikan dengan Teorema 4.5.
Teorema 4.5 Diberikan bilangan bulat $n \geq 3, r \geq 1$ dan bilangan genap $q \geq 2$, graph lobster $L_{n}(q, r)$ memiliki pelabelan selimut total super $\quad\left(2 n q^{2} r^{2}+3 n q^{2}+4 n q r^{2}+7 n q r-\right.$ $\left.12 n q+6 n r q^{2}-16 n r-22 n+2,1\right)-$ $L_{2}(q, r)$ antimagic.

Bukti. Diberikan suatu graph lobster $L_{n}(q, r)$ dengan bilangan bulat $n \geq 3, r \geq 1$ dan bilangan genap $q \geq 2$. Misalkan $\xi_{1}$ adalah fungsi bijektif dari $E\left(L_{n}(q, r)\right) \cup V\left(L_{n}(q, r)\right)$ pada $\quad\{1,2,3, \ldots, 2 n(1+q+q r)\} \quad$ dengan $\xi_{1}\left(V\left(L_{n}(q, r)\right)\right)=\{1,2,3, \ldots, n(1+q+q r)\}$. Himpunan semua label vertex pada graph lobster $L_{n}(q, r)$ adalah $X=[1, n(1+q+q r)]$, dan label edge adalah $\quad Y=$ $[n(1+q+q r)+1,2 n(1+q+q r)-]$.

Selanjutnya himpunan $X$ dipartisi menjadi tiga subhimpunan yaitu $X=B \cup D \cup F$, dengan $B=[1, n)]$, $D=[n+1, n(q+1)]$ $F=[n(q+1)+1, n(q+1+q r)]$.

Himpunan $Y$ dipartisi menjadi tiga subhimpunan yaitu $Y=P \cup Q \cup R$, dengan $P=[n(q+1+q r)+1, n(q+2+q r)-1]$, $Q=[n(q+2+q r), n(2 q+2+q r)-1]$, $R=[n(2 q+2+q r), 2 n(q+q r+1)]$.

Didefinisikan pelabelan $\xi_{1}$ pada $L_{n}(q, r)$. Pertama akan dilakukan pelabelan vertex vertex pada $L_{n}(q, r)$. Labeli vertex backbone dengan elemen dari $B$ dilakukan dari vertex paling atas ke vertex paling bawah, sehingga diperoleh $\sum B_{i}=i$ untuk $1 \leq i \leq n$. Kemudian labeli vertex hand dengan elemen dari $D$. Berdasarkan Lemma 4.1 dengan $x=n+1 ; k=n ; 2 y=q \quad$ diperoleh $\quad D$ merupakan $n$-seimbang. Dengan menggunakan persamaan (1) diperoleh $\sum D_{i}=\frac{n q^{2}}{2}+\frac{q}{2}-2 n-$ 1. Selanjutnya labeli vertex finger dengan elemen dari $F$. Berdasarkan Lemma 4.1 dengan $x=n(q+1)+1 ; k=n ; 2 y=q r, \quad$ diperoleh $F \quad$ merupakan $n$-seimbang. Dengan menggunakan persamaan (1) diperoleh $\sum F_{i}=$ $\frac{n q^{2} r^{2}}{2}+n r q^{2}+\frac{q r}{2}-2 n q-2 n-1$.

Selanjutnya akan dilakukan pelabelan edgeedge pada $L_{n}(q, r)$. Gunakan elemen dari $P$ 
untuk melabeli edge yang menghubungkan vertex-vertex backbone dilakukan dari vertex paling bawah ke vertex paling atas, sehingga diperoleh $\quad \sum P_{h}=n(2+q+q r)-h$ untuk $1 \leq h \leq n-1$. Labeli edge yang menghubungkan vertex backbone dan vertex hand dengan elemen dari $Q$. Berdasarkan Lemma 4.1 dengan $x=n(q+2+q r)$; $k=n, 2 y=q$ diperoleh $Q$ merupakan $n$ seimbang. Dengan menggunakan persamaan (1) diperoleh $\quad \sum Q_{i}=n q^{2}+2 n q r-\frac{n q}{2}-4 n r-$ $\frac{q}{2}-4 n+1$. Selanjutnya labeli edge yang menghubungkan vertex hand dan vertex dengan elemen dari $R$. Berdasarkan Lemma 4.1 dengan $x=2 n(q+1+r) ; k=n, 2 y=q r \quad$ diperoleh $R \quad$ merupakan $n$-seimbang. Dengan menggunakan persamaan (1) diperoleh $\sum R_{i}=\frac{n q^{2} r^{2}}{2}+2 n q r^{2}+2 n r q^{2}+n q r-\frac{q r}{2}-$ $4 n q-4 n r-4 n+1$.

Dimisalkan $\omega\left(H_{h}\right)$ untuk $1 \leq h \leq n-1$ adalah bobot setiap graph lobster $L_{n}(q, r)$ yang isomorfik dengan $L_{2}(q, r)$. Kemudian untuk setiap $1 \leq h \leq n-1$ diperoleh

$$
\begin{aligned}
\omega\left(H_{h}\right)= & \sum_{i=0}^{1} B_{i+h}+2 \sum D_{i}+2 \sum F_{i}+P_{h} \\
& +2 \sum Q_{i}+2 \sum R_{i} \\
= & 2 n q^{2} r^{2}+3 n q^{2}+4 n q r^{2}+7 n q r \\
& -12 n q+6 n r q^{2}-16 n r-22 n+h+1
\end{aligned}
$$

Dengan mengurangkan $\omega\left(H_{h+1}\right)$ dengan $\omega\left(H_{h}\right)$ diperoleh nilai $d=1$ dan nilai $a$ adalah $2 n q^{2} r^{2}+3 n q^{2}+4 n q r^{2}+7 n q r-12 n q$ $+6 n r q^{2}-16 n r-22 n+2$

Pola pelabelan yang telah diberikan pada Teorema 4.5, menjadi dasar munculnya Akibat 4.6 yang menjelaskan pola pelabelan selimut total super $(a, 3)-L_{2}(q, r)$ antimagic pada graph lobster $L_{n}(q, r)$.

Akibat 4.6 Diberikan bilangan bulat $n \geq 3$, $r \geq 1$ dan bilangan genap $q \geq 2$, graph lobster $L_{n}(q, r)$ memiliki pelabelan selimut total super $\left(2 n q^{2} r^{2}+3 n q^{2}+4 n q r^{2}+7 n q r-12 n q+\right.$ $\left.6 n r q^{2}-16 n r-22 n+4,3\right)-L_{2}(q, r)$ antimagic.

Bukti. Graph $L_{n}(q, r)$ dilabeli dengan menggunakan pola pelabelan sesuai dengan Teorema 4.5 untuk vertex backbone, vertex hand, vertex finger, edge yang menghubungkan vertex backbone dengan vertex hand, dan edge yang meghubungkan vertex hand dengan vertex finger. Edge yang saling menghubungkan vertex backbone dilabeli dengan elemen dari $P$ dilakukan dari vertex paling atas ke vertex paling bawah sehingga diperoleh $\sum P_{h}=(n(1+q+$ $q r)+h)$ untuk $1 \leq h \leq n-1$. Kemudian untuk setiap $1 \leq h \leq n-1$ diperoleh

$$
\begin{aligned}
\omega\left(H_{h}\right)= & \sum_{i=0}^{1} B_{i+h}+2 \sum D_{i}+2 \sum F_{i}+P_{h} \\
& +2 \sum Q_{i}+2 \sum R_{i} \\
= & 2 n q^{2} r^{2}+3 n q^{2}+4 n q r^{2}+7 n q r \\
& -12 n q+6 n r q^{2}-16 n r-22 n \\
& +3 h+1 .
\end{aligned}
$$

Dengan mengurangkan $\omega\left(H_{h+1}\right)$ dengan $\omega\left(H_{h}\right)$ diperoleh nilai $d=3$. Diperoleh nilai $a$ adalah $2 n q^{2} r^{2}+3 n q^{2}+4 n q r^{2}+7 n q r-12 n q$ $+6 n r q^{2}-16 n r-22 n+4$

Ilustrasi pelabelan selimut total super $(a, 1)-L_{2}(4,5)$ antimagic pada graph lobster $L_{4}(4,5)$ disajikan pada Contoh 4.7. Selain itu, contoh pelabelan selimut total super $(a, 3)-$ $L_{2}(4,5)$ antimagic pada graph lobster $L_{4}(4,5)$ disajikan pada Gambar 5.

Contoh 4.7 Diberikan graph lobster $L_{4}(4,5)$ yang memiliki tiga subgraph yang isomorfik dengan $L_{2}(4,5)$. Gambar 4 merupakan graph lobster $L_{4}(4,5)$ yang dilabeli berdasarkan Teorema 4.6. Himpunan semua label vertex pada graph lobster $L_{4}(4,5)$ menggunakan himpunan $X=[1,100]$, dan label edge menggunakan himpunan $Y=[101,199]$. Elemen dari himpunan $X=[1,100]$ dipartisi menjadi tiga subhimpunan $\quad X=B \cup D \cup F$, dengan $B=$ $[1,4], D=[5,20]$ dan $F=[21,100]$. Himpunan $Y$ dipartisi menjadi tiga subhimpunan, $P=$ [101,103], $Q=[104,119]$, dan $R=[120,199]$.

Pertama akan dilakukan pelabelan vertex vertex pada $L_{n}(q, r)$. Labeli vertex backbone dengan elemen dari $B$ dilakukan dari vertex paling atas ke vertex paling bawah, sehingga diperoleh elemen dari $B_{h}$ adalah $\{h\}$ untuk $1 \leq h \leq 4$. Kemudian labeli vertex hand dengan 
elemen dari $D$. Selanjutnya labeli vertex finger dengan dengan elemen dari $F$. Berdasarkan Lemma 4.1 dengan $x=21, k=4, y=10, F$ merupakan 4-seimbang.

Selanjutnya akan dilakukan pelabelan edgeedge pada $L_{4}(4,5)$. Gunakan elemen dari $P$ untuk melabeli edge yang menghubungkan vertex-vertex backbone dilakukan dari vertex paling bawah ke vertex paling atas. Labeli edge yang menghubungkan vertex backbone dan vertex hand dengan elemen dari $Q$. Berdasarkan Lemma 4.1 dengan $x=104, k=4, y=2, Q$ merupakan 4-seimbang.

Selanjutnya labeli edge yang menghubungkan vertex hand dan vertex dengan elemen dari $R$. Berdasarkan Lemma 4.1 dengan $x=120, k=4, y=10, \quad R \quad$ merupakan $\quad 4$ seimbang.

Berdasarkan persamaan (9) pada Teorema 4.6, dapat dicari nilai $a$ adalah $a=\omega\left(H_{1}\right)=$ 6874 dengan $d=1$. Ilustrasi pelabelan selimut total super $(6874,1)-L_{2}(4,5)$ antimagic pada graph lobster $L_{4}(4,5)$ disajikan pada Gambar 4.

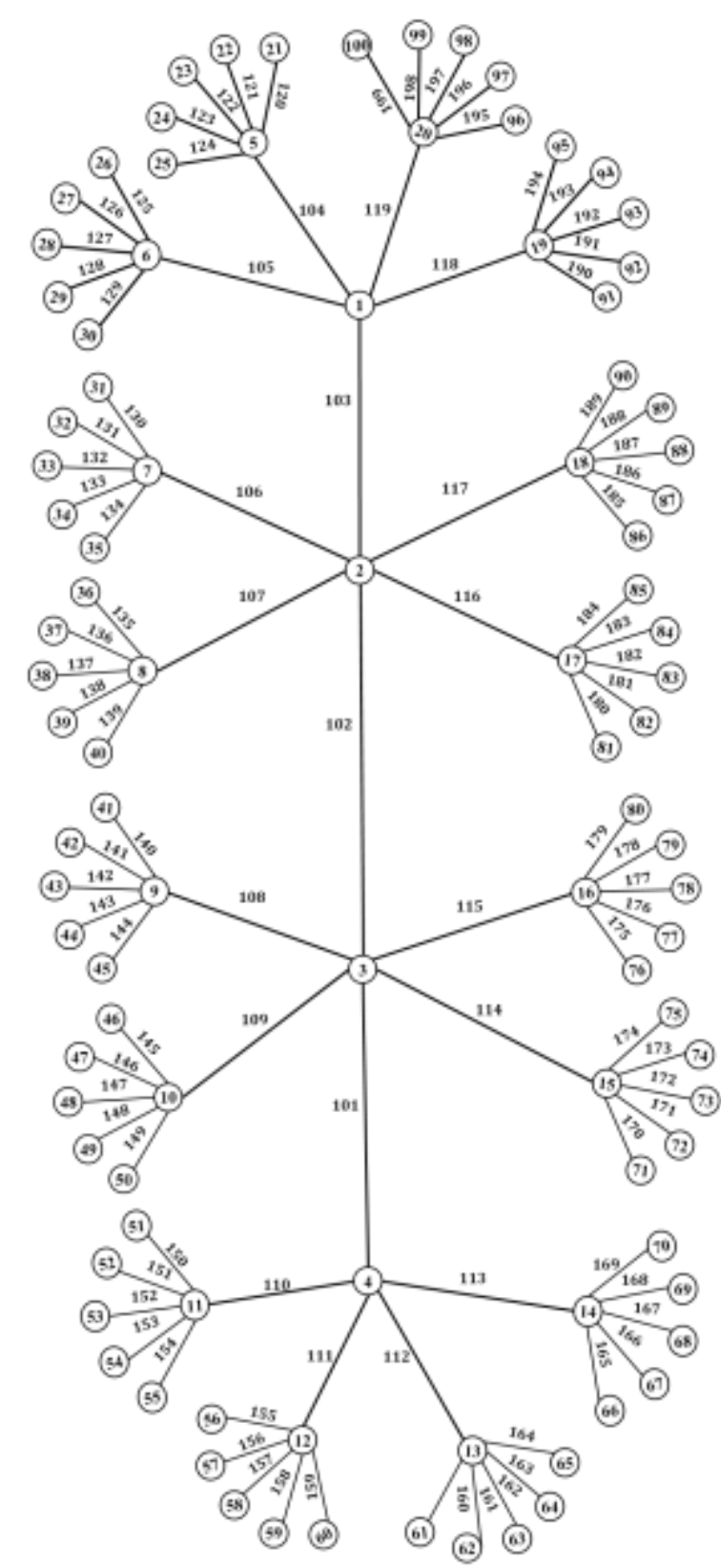

Gambar 4. Pelabelan selimut total super $(\mathbf{6 8 7 4}, \mathbf{1})-$ $\boldsymbol{L}_{\mathbf{2}}(\mathbf{4}, \mathbf{5})$ antimagic pada graph lobster $L_{4}(4,5)$ 


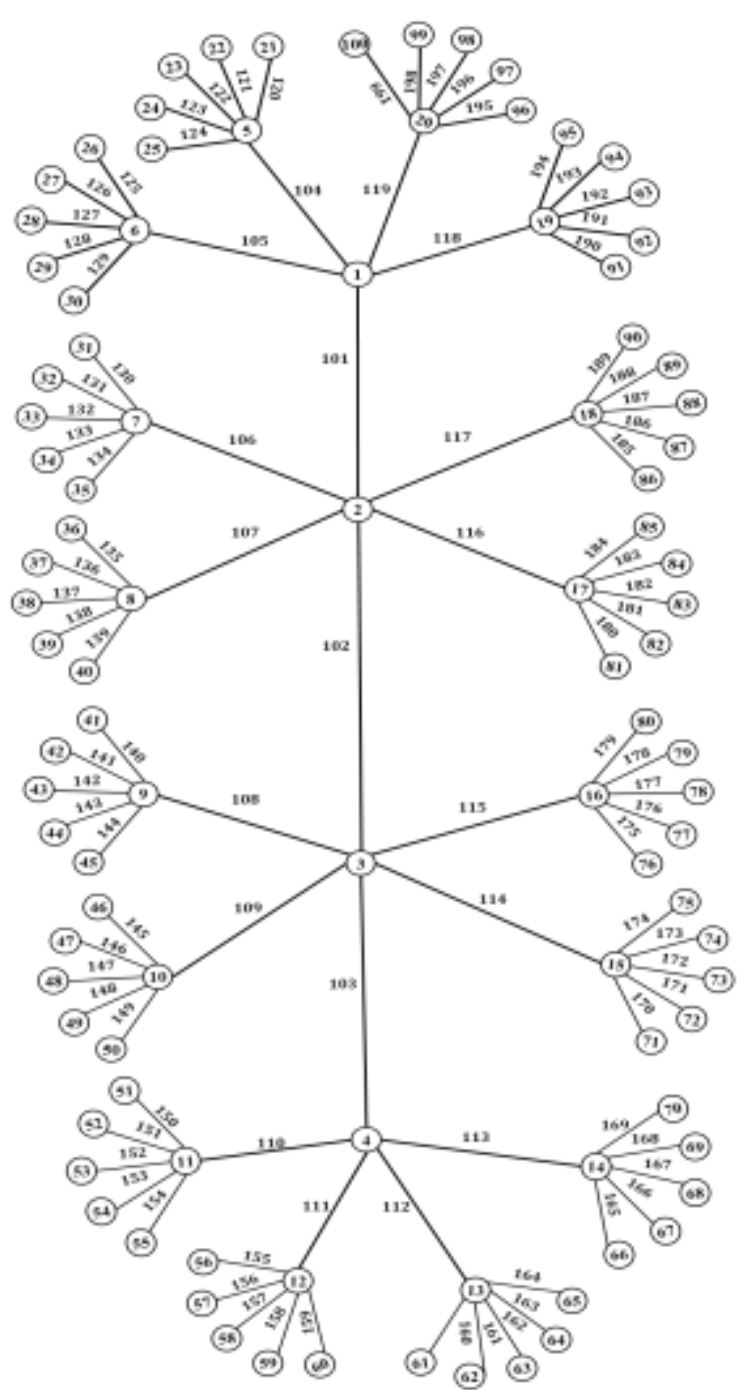

Gambar 5. Pelabelan selimut total super $(6876,3)-$ $L_{2}(4,5)$ antimagic pada graf lobster $L_{4}(4,5)$

\section{KESIMPULAN DAN SARAN}

\section{Kesimpulan}

Penelitian ini menghasilkan kesimpulan bahwa graph lobster $L_{n}(q, r)$ untuk $n, r, q$ bilangan bulat dengan $n \geq 2, r \geq 1, q \geq 2$ genap memiliki pelabelan selimut total super $\left(2 n q^{2} r^{2}+3 n q^{2}+4 n q r^{2}+7 n q r-12 n q+\right.$ $\left.6 n r q^{2}-16 n r-22 n+d+1, d\right)-L_{2}(q, r)$ antimagic untuk $d \in\{1,3\}$.

\section{Saran}

Bagi pembaca yang tertarik dengan pelabelan selimut total super $(a, d)-$ $H$ antimagic dapat memperluas kajian penelitian selanjutnya dengan menggunakan selimut lain atau mencari nilai d yang belum dicari dalam penelitian ini.

\section{DAFTAR PUSTAKA}

Azizah, I. dan Dafik. 2015. Super (a; d)-HAntimagic Total Selimut pada Graph Triangular Cycle Ladder untuk Pengembangan Ciphertext. Seminar Nasional Matematika dan Pembelajarannya. Universitas Negeri Jember.

Gallian, Joseph A. 2015. "A Dynamic Survey of Graph Labelling". The Electronic Journal of Combinatorics. 6, p.1-389.

Gumilar, P. G. D., Harini, L. P. I. dan Sari, Kartika. 2013. "Dimensi Metrik Graph Lobster $L_{n}(q ; r)$ ". E-Jurnal Matematika Universitas Udayana, 2(2), p.42-46.

Gutiérrez, A. dan Lladó, A. 2005. "Magic Coverings". JCMCC, 55, p.43-56.

Hartsfield, N. dan Ringel, G.. 1990. Pearls in Graph Theory. San Diego : Academic Press.

Hegde, S.M. 2012. Labeled Graphs and Digraphs : Theory and Applications. India : National Institute of Technology Karnataka.

Inayah N., Simanjuntak R., Salman, A. N. M. dan Syuhada, K.I.A. 2013. "Super $(a, d)-$ $\mathrm{H}$-antimagic total labelings for shackles of a connected graph $H^{\prime}$. Australasian Journal Of Combinatorics, 57, p.127-138.

Kathiresan, K.M and Laurence, S. D. 2015. "On Super $(a, d)-H$ Antimagic Total Covering of Star Related Graphs". Discussiones Mathematicae Graph Theory, 35, p.755-764.

Khan, N., Pal, A. dan Pal, M. 2009. "Edge colouring of Cactus Graphs". AMO Advanced Modelling and Optimization. 11(4).

Prasanna, L. N. 2014. "Application of Graph Labelling in Communication Networks". Orient. J.Comp. Sci. and Technol, 7(1)

Roswitha, M. , Baskoro, E.T, Maryati, T.K., Kurdhi, N.A., dan Susanti, I. 2013. "Further Results On Cycle-Supermagic Labeling". AKCE International Journal Of Graphs And Combinatorics, 10 (2), p.211-220.

Sari, F.K.. 2014. Pelabelan Selimut $(a, d)-H$ Anti Ajaib Super Pada Graph Pohon Pisang, Kembang Api, dan Buku. Skripsi. Universitas Sebelas Maret.

Wailis, W. D.. 2001. Magic Graph. Berlin : Birkhauser Boston. 